\title{
Produtividade de grãos e óleo de genótipos de amendoim para o mercado oleoquímico ${ }^{1}$
}

\author{
Grain and oil yield of peanut genotypes for the oil chemistry market
}

\author{
Roseane Cavalcanti dos Santos ${ }^{2 *}$, Rosa Maria Mendes Freire ${ }^{2}$, Liziane Maria Lima ${ }^{2}$, Giuliano Fernandes \\ Zagonel $^{3}$ e Bill Jorge Costa ${ }^{3}$
}

\begin{abstract}
Resumo - Linhagens de elite e cultivares de amendoim rasteiro foram avaliadas quanto às suas produtividades de grãos e de óleo, visando uma posterior indicação ao mercado de óleo comestível ou combustível. Os genótipos foram cultivados no período das águas, durante dois anos, em Barbalha, CE, sob o delineamento experimental de blocos ao acaso, com cinco repetições. A colheita foi efetuada entre 110 e 135 dias após o plantio. As variáveis analisadas foram produtividade em vagens, sementes e óleo. O óleo bruto foi extraído aplicando-se a tecnologia convencional de soxhlet, utilizando-se éter de petróleo como solvente. Posteriormente, procedeu-se às análises dos ácidos graxos por meio de cromatografia gasosa. Baseando-se nos ensaios de produção, os materiais de maior produção de grãos foram LViPE-06 e BRS Pérola Branca, com médias de 3,04 tha ${ }^{-1}$ de vagens e 2,13 $\mathrm{t} \mathrm{ha}^{-1}$ de sementes. Esses materiais também se destacaram para o segmento oleoquímico, baseando-se no teor de óleo e na relação de ácidos graxos O/L, que se situaram em $51 \%$ e 1,9 , respectivamente.
\end{abstract}

Palavras-chave - Arachis hypogaea. Estabilidade oxidativa. Óleo de amendoim. Biodiesel.

\begin{abstract}
Top lines and cultivars of runner peanut genotypes were analyzed as to grain and oil yield, aiming further recommendation to edible or combustible oil market. The genotypes were cultivated during wet seasons for two years, at the city of Barbalha, state of Ceará, Brazil, by using a complete randomized block design with five replicates. The harvest took place from 110 to 135 days after planting. Pod, grain and oil yields were registered in each plot. Crude oil was extracted by soxhlet protocol, by using petroleum ether as a solvent. Afterwards, fatty acids were analyzed by gas chromatography. Based on yield tests, LViPE-06 and BRS Pérola Branca showed the highest grain yields, with pod and seed yield averages of $3.04 \mathrm{~kg} \mathrm{ha}^{-1}$ and $2.13 \mathrm{~kg} \mathrm{ha}^{-1}$, respectively. These genotypes also stood out as to oil chemistry industry, based on oil content and ratio of oleic/ linoleic fatty acids, which were 51 and 1.9, respectively.
\end{abstract}

Key words - Arachis hypogaea. Oxidative stability. Oleic/linoleic ratio. Biodiesel.

\footnotetext{
* Autor para correspondência

${ }^{1}$ Recebido para publicação em 17/12/2010; aprovado em 15/06/2011

Pesquisa desenvolvida pela Empresa Brasileira de Pesquisa Agropecuária e financiada pelo Banco do Nordeste do Brasil

${ }^{2}$ Embrapa Algodão, Caixa Postal 174, Campina Grande-PB, Brasil, 58428-095, caval@cnpa.embrapa.br, rosa@cnpa.embrapa.br, liziane@ cnpa.embrapa.br

${ }^{3}$ Instituto de Tecnologia do Paraná - TECPAR, Curitiba-PR, Brasil, gzagonel@tecpar.br, billcosta@tecpar.br
} 


\section{Introdução}

A demanda por óleos de origem vegetal vem crescendo significativamente na última década em virtude do crescimento do mercado oleoquímico, especialmente nos segmentos de biodiesel, alimentos e cosméticos (COSTA; ZAGONEL, 2009). Em relação ao biodiesel, atualmente a soja tem sido mais usada para esse fim, embora possua baixo teor de óleo nas sementes, em torno de 20\% (LÉLIS et al., 2010; MINUZZI et al., 2009). Para que esse mercado continue em ascensão, é necessário manter o fluxo da matéria-prima para as indústrias, de modo a garantir o estabelecimento das cadeias produtivas do setor.

Uma característica muito importante nesse setor é a proporção dos ácidos graxos, especialmente os ácidos oleico, linoleico e linolênico, responsáveis pela estabilidade oxidativa (COSTA; ZAGONEL, 2009; WARNER; FEHR, 2008).

O amendoim é uma oleaginosa mundialmente cultivada, com uma produção de 31,48 milhões de toneladas em grãos, liderada pela China (33\%), Índia (18\%) e EUA (7\%), segundo dados do USDA (2010), e com uma produção de óleo estimada em 6 milhões de toneladas. Os grãos de amendoim têm várias opções de consumo para os segmentos alimentícios e oleoquímicos, com teores de óleo variando de 44 a 56\% (CAMPOSMONDRAGON et al., 2009).

Em termos de ácidos graxos, comparando-se com o óleo da soja, o amendoim contém, em média, 41 e $38 \%$ dos ácidos oleico e linoleico, respectivamente, contra 24 e $55 \%$ do óleo da soja (BOLTON; SANDERS, 2002; CAMPOS-MONDRAGÓN et al., 2009; COSTA; ZAGONEL, 2009). A relação dos ácidos graxos oleico/linoleico $(\mathrm{O} / \mathrm{L})$ é um importante indicador da estabilidade do óleo e, portanto, uma maior vida de prateleira (ISLEIB et al., 2006; SINGKHAM et al., 2010). Essas características dão uma indicação da maior resistência à rancificação, o que é um fator importante no aspecto sensorial do óleo para fim comestível.

O teor de ácido linolênico é outro fator relacionado com a estabilidade. De acordo com Fehr (2007), quando o óleo possui baixo teor de ácido linolênico e alto teor de ácido oleico, ele tem maior estabilidade oxidativa (GERD et al., 2007).

No Brasil, a produção do amendoim vem se restabelecendo anualmente, situando-se em torno de 300.000 toneladas. A lavoura é conduzida por cultivares eretas e rasteiras (runner), sendo essas últimas mais expressivas no Sudeste brasileiro (SANTOS et al., 2005). Na região Nordeste, as cultivares de porte ereto são mais adotadas pelos agricultores, embora a demanda por cultivares rasteiras e com alto teor de óleo venha crescendo significativamente nos últimos cinco anos, devido à expansão do mercado oleoquímico (SANTOS et al., 2010). Tal demanda tem promovido uma ampliação nas linhas de pesquisa de melhoramento genético, visando gerar novas cultivares para atender aos mercados de óleo comestível e combustível (JONNALA et al., 2005; OLIVEIRA et al., 2006).

Considerando-se o potencial de expansão do mercado de óleo e derivados na região Nordeste, é interessante conhecer o padrão de produção de grãos e óleo de vários genótipos, de modo a melhor orientar os produtores nos aspectos de recomendação de cultivares ou de linhagens potenciais para atender a esse segmento. Neste trabalho, apresentam-se resultados a respeito do desempenho produtivo de genótipos rasteiros de amendoim, cultivados na região semiárida do Ceará, e avaliados para a produção de grãos e óleo, visando uma posterior indicação de cultivar para o mercado oleoquímico.

\section{Material e métodos}

Oito genótipos de amendoim rasteiro, constituídos por linhagens de elite (top lines) e cultivares, foram avaliados em regime de sequeiro, com suplementação hídrica, durante dois anos (2008 e 2009), no município de Barbalha, CE (07²18'18"S

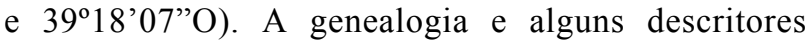
agronômicos dos genótipos avaliados encontramse na Tabela 1. A cultivar ereta e precoce BR 1 foi usada como testemunha geral, por ser produtiva e adaptada ao semiárido (SANTOS et al., 2010). O solo, caracterizado como Neossolo flúvico de textura arenosa e média, foi previamente adubado e corrigido em virtude das necessidades de fertilizante e corretivo revelados na análise de solo. A semeadura foi realizada em julho, sob o espaçamento de $0,7 \mathrm{~m} \times 0,2 \mathrm{~m}$, tendo-se deixado duas sementes porcova. A parcela foi constituída de três fileiras de $5 \mathrm{~m}$ de comprimento, tendo-se utilizado a central como área útil, e tendo-se descartado $30 \mathrm{~cm}$ de cada extremidade (bordadura). O delineamento experimental adotado foi o de blocos ao acaso, com nove tratamentos e cinco repetições. Os tratos culturais e fitossanitários foram realizados segundo a recomendação de Santos et al. (2006). A colheita foi efetuada de 110 a 135 dias após a emergência (DAE); e a BR 1 foi colhida aos 87 DAE. As variáveis analisadas foram, produtividade em vagens, sementes e óleo. Para estimar o teor de óleo, por meio de Ressonância Magnética Nuclear (RMN), as sementes foram utilizadas ao final de cada ensaio, quando se encontravam com 8 a $10 \%$ de umidade. 
Tabela 1 - Genealogia, origem e alguns descritores agronômicos dos genótipos de amendoim

\begin{tabular}{lccccccc}
\hline \multirow{2}{*}{ Genótipo } & Genealogia/origem & Ciclo & P100 $(\mathrm{g})$ & \multicolumn{3}{c}{ Semente } \\
\cline { 6 - 8 } & & & $\mathrm{CAr}$ & $\mathrm{T}$ & $\mathrm{F}$ & $\mathrm{N} / \mathrm{V}$ \\
\hline BR1 & Cultivar/ PB, Brasil & $85-87$ & $45-49$ & $\mathrm{~V}$ & $\mathrm{M}$ & $\mathrm{Ar}$ & $3-4$ \\
BRS Pérola Branca & Cultivar/ PB, Brasil & $110-115$ & $65-70$ & $\mathrm{Br}$ & $\mathrm{G}$ & $\mathrm{Ar}$ & $3-4$ \\
LB02/08 & Top line/ PB, Brasil & $115-120$ & $55-60$ & $\mathrm{Br}$ & $\mathrm{M}$ & $\mathrm{Ar}$ & $2-3$ \\
LB03/08 & Top line/ PB, Brasil & $115-120$ & $55-60$ & $\mathrm{Br}$ & $\mathrm{M}$ & $\mathrm{Al}$ & $2-3$ \\
LB04/08 & Top line/ PB, Brasil & $115-120$ & $55-60$ & $\mathrm{Br}$ & $\mathrm{G}$ & $\mathrm{Al}$ & $2-3$ \\
LB05/08 & Top line/ PB, Brasil & $110-115$ & $65-70$ & $\mathrm{Br}$ & $\mathrm{G}$ & $\mathrm{Ar}$ & $3-4$ \\
LViPE-06 & Top line/, PE, Brasil & $120-125$ & $85-90$ & $\mathrm{~B}$ & $\mathrm{EG}$ & $\mathrm{Ar}$ & $1-2$ \\
LGoPE-06 & Top line/ PE, Brasil & $125-130$ & $85-90$ & $\mathrm{~B}$ & $\mathrm{EG}$ & $\mathrm{Ar}$ & $1-2$ \\
Florunner & Cultivar/ EUA & $120-130$ & $65-70$ & $\mathrm{~B}$ & $\mathrm{G}$ & $\mathrm{Al}$ & $1-2$ \\
\hline
\end{tabular}

${ }^{(1)}$ Linhagens avançadas $\left(\mathrm{F}_{8-9}\right)$, geradas por cruzamento entre BR $1(+)$ e LViPE-06 ( $\overbrace{}^{\Uparrow})$; (2) Linhagens selecionadas de land races nativas do Agreste pernambucano; DAE: dias após a emergência; P100: peso médio de 100 sementes; Cor: B- bege, V- vermelha e Br- branca; T (tamanho): P- pequeno, M- médio, G- grande e EG- extragrande; F (forma): Ar- arredondada e Al- alongada; N/V: número de sementes/vagem

Após a tabulação dos dados, procedeu-se à análise de variância pelo teste $\mathrm{F}$ e à análise de comparação de médias (Tukey, $\mathrm{p}<0,05$ ), tendo-se utilizado o programa GENES, versão 2006.4.1 (CRUZ, 2006).

Para as análises de ácidos graxos, foram consideradas as sementes dos materiais colhidos em 2009. Após a colheita, as vagens de cada genótipo foram beneficiadas e secadas em condições naturais até que as sementes estivessem com 8 a $10 \%$ de umidade. O óleo bruto de cada genótipo foi obtido no extrator de soxhlet, por cerca de seis horas, sob aquecimento, tendo-se utilizado o éter de petróleo como solvente, no Laboratório de Apoio Multidisciplinar, da EMBRAPA Algodão.

O perfil de ácidos graxos foi obtido no Laboratório de Divisão de Biocombustíveis do Instituto de Tecnologia do Paraná (TECPAR), por meio de cromatografia gasosa. O método de preparação da amostra de óleo teve por base a norma da AOCS Ce2 66 (09), em que cerca de $250 \mathrm{mg}$ de óleo foram pesados em um tubo de ensaio $(20 \mathrm{~mL})$, e adicionados $3 \mathrm{~mL}$ da solução $0,5 \mathrm{~N}$ de $\mathrm{NaOH}$ em metanol. O tubo fechado foi incubado em banho ultrassônico a $60^{\circ} \mathrm{C}$, por 1 hora. A seguir, foram adicionados $5 \mathrm{~mL}$ de heptano, e $10 \mathrm{~mL}$ de solução aquosa saturada de $\mathrm{NaCl}$, sob agitação. Os tubos foram colocados em repouso para separação de fases. A fase orgânica superior foi coletada e foi adicionado $\mathrm{Na}_{2} \mathrm{SO}_{4}$ anidro (1 g ou o suficiente para garantir a absorção da água presente na fase orgânica), para redução do teor de água. Alíquotas dessa fase orgânica seca foram analisadas em cromatógrafo gasoso.

Para a análise dos ésteres metílicos dos óleos de amendoim, utilizou-se o cromatógrafo a gás $\mathrm{CG}$, da
Varian CP-3800, acoplado a um detector de ionização de chama (FID), operando com injetor de split na razão de 1:50, para a injeção de $1 \mu \mathrm{L}$ de volume. A temperatura do injetor e do detector foi de $250{ }^{\circ} \mathrm{C}$. Uma coluna capilar Select Biodiesel - FAME foi empregada a $210{ }^{\circ} \mathrm{C}$, com dimensões de $30 \mathrm{~cm}$ x 0,32 mm x 0,25 mm. O nitrogênio foi usado como gás de arraste à vazão de $2 \mathrm{~mL} \min ^{-1}$. Todas as análises foram efetuadas com duas repetições.

A identificação dos ácidos graxos foi feita por comparação do tempo de retenção, tendo-se utilizado padrões da Sigma-Aldrich. Após a obtenção dos dados, calculou-se a média de cada amostra e os respectivos desvios-padrão.

\section{Resultados e discussão}

O resumo da análise de variância e as médias de produtividade de vagens, sementes e óleo dos genótipos de amendoim avaliados encontram-se na Tabela 2. Foram observadas diferenças estatísticas significativas entre os tratamentos e a interação $\mathrm{G}$ x A, indicando que os genótipos tiveram um rendimento diferenciado nos diferentes anos analisados.

Observou-se que os materiais mais produtivos foram LViPE-06 (grãos extragrandes) e a cultivar BRS Pérola Branca (grãos grandes), com médias de 3,04 t ha ${ }^{-1}$ de vagens e $2,13 \mathrm{t} \mathrm{ha}^{-1}$ de sementes, correspondendo a uma elevação na ordem de 6,5 e $9 \%$, respectivamente, sobre a média geral dos genótipos rasteiros. $\mathrm{O}$ rendimento em sementes, contudo, foi maior na BRS Pérola Branca (71\%), embora a produtividade de óleo dos dois genótipos 
tenha se situado em $1,1 \mathrm{t} \mathrm{ha}^{-1}$ (TAB. 2).

O teor de óleo nas sementes ficou em torno de $49 \%$ (TAB. 2), dentro da média encontrada em cultivares de amendoim (CAMPOS-MONDRAGON et al., 2009). Os materiais de maior destaque foram BRS Pérola Branca, LViPE-06 e LGoPE-06, com uma média superior a 51\%.

O perfil de ácidos graxos dos genótipos deste estudo encontra-se na Tabela 3. Para o segmento oleoquímico, a estabilidade do óleo e sua vida de prateleira são quesitos importantes. Os genótipos LViPE-06, LGoPE-06 e BRS Pérola Branca destacamse entre os demais, considerando-se os teores do ácido oleico e a relação oleico/linoleico $(\mathrm{O} / \mathrm{L})$ superior a 1,8 . No Brasil, as cultivares comerciais com maior relação O/L são as tardias IAC Caiapó e Runner IAC 886, com valores de $\mathrm{O} / \mathrm{L}$ de 1,5 a 2,0 .

Observou-se que a relação $\mathrm{O} / \mathrm{L}$ está altamente correlacionada com a vida de prateleira: quanto maior a relação, maior a resistência à rancificação dos produtos derivados (BOLTON; SANDERS, 2002; SANTOS et al., 2005; SINGKHAM et al., 2010). Atualmente, várias instituições de pesquisa nacionais e internacionais têm envidado esforços para elevar a proporção do ácido oleico nas sementes de amendoim, com níveis de até $80 \%$, reduzindo consideravelmente a concentração do ácido linoleico e elevando a relação $\mathrm{O} / \mathrm{L}$ para acima de 2 , além de cooperar para a melhoria das propriedades fitoquímicas do óleo (BOLTON; SANDERS, 2002; CAMPOSMONDRAGON et al., 2009). Bolton e Sanders (2002) citam trabalhos de pesquisadores da Flórida que analisaram 500 acessos de amendoim e identificaram dois materiais com relação O/L próxima a 35; reportam, também, sobre outros trabalhos em que os autores conseguiram identificar genótipos com relação $\mathrm{O} / \mathrm{L}$ na faixa de 15, denotando o lastro de variabilidade genética para esse caráter. Em tais materiais, os autores reportam que a estabilidade oxidativa foi de 3,4 a 14,5 vezes superior à das cultivares convencionais. No Brasil, a EMBRAPA e o Instituto Agronômico de Campinas coordenam um programa nesse segmento, com linhagens

Tabela 2 - Resumo da análise de variância e produtividade média de vagens, sementes e óleo de amendoim. Barbalha, CE

\begin{tabular}{|c|c|c|c|c|c|}
\hline \multirow{2}{*}{ FV } & & \multirow{2}{*}{ GL } & \multicolumn{3}{|c|}{ QM para produtividade } \\
\hline & & & Vagem & Semente & Óleo \\
\hline Genótipo (G) & & 8 & $1739111,78^{* *}$ & $1103661,64 * *$ & $384176,98^{* *}$ \\
\hline Anos (A) & & 1 & $26434947,71 * *$ & $13091598,55 * *$ & $3246538,82 * *$ \\
\hline GxA & & 8 & $1100376,64 * *$ & $642801,79 * *$ & $160226,49 * *$ \\
\hline Tratamentos & & 17 & $2891226,77 * *$ & $1591959,18^{* *}$ & $447162,74^{* *}$ \\
\hline Blocos & & 4 & $179748,33^{\text {ns }}$ & $121864,71^{\mathrm{ns}}$ & $24310,86^{\mathrm{ns}}$ \\
\hline Resíduo & & 68 & 373164,37 & 186228,81 & 44425,01 \\
\hline Total & & 89 & & & \\
\hline \multirow{2}{*}{ Genótipo } & \multicolumn{2}{|c|}{ Produtividade $\left(\mathrm{t} \mathrm{ha}^{-1}\right)$} & \multirow{2}{*}{$\begin{array}{c}\text { Rendimento em sementes } \\
(\%)\end{array}$} & \multicolumn{2}{|c|}{ Óleo } \\
\hline & Vagens & Sementes & & Teor $(\%)$ & Prod. $\left(\mathrm{t} \mathrm{ha}^{-1}\right)$ \\
\hline BR 1 & $1,85 \mathrm{c}$ & $1,33 \mathrm{c}$ & 72 & $45,34 \mathrm{bc}$ & $0,60 \mathrm{c}$ \\
\hline BRS Pérola Branca & $3,02 \mathrm{a}$ & $2,14 \mathrm{a}$ & 71 & $51,20 \mathrm{a}$ & $1,08 \mathrm{a}$ \\
\hline LB02/08 & $2,83 \mathrm{ab}$ & $1,90 \mathrm{ab}$ & 67 & $45,32 \mathrm{bc}$ & $0,86 \mathrm{~b}$ \\
\hline LB03/08 & $2,61 \mathrm{~b}$ & $1,83 \mathrm{~b}$ & 70 & $48,30 \mathrm{~b}$ & $0,88 \mathrm{~b}$ \\
\hline LB04/08 & $2,70 \mathrm{~b}$ & $1,87 \mathrm{~b}$ & 68 & $45,10 \mathrm{bc}$ & $0,84 \mathrm{~b}$ \\
\hline LB05/08 & $2,96 \mathrm{a}$ & $1,98 \mathrm{ab}$ & 70 & $49,56 \mathrm{ab}$ & $0,97 \mathrm{ab}$ \\
\hline LViPE-06 & $3,13 \mathrm{a}$ & $2,15 \mathrm{a}$ & 69 & $51,81 \mathrm{a}$ & $1,10 \mathrm{a}$ \\
\hline LGoPE-06 & $2,85 \mathrm{ab}$ & $1,95 \mathrm{ab}$ & 68 & $51,96 \mathrm{a}$ & $1,02 \mathrm{a}$ \\
\hline Florunner & $2,66 \mathrm{~b}$ & $1,95 \mathrm{ab}$ & 67 & $49,37 \mathrm{ab}$ & $0,96 \mathrm{ab}$ \\
\hline Média & 2,73 & 1,90 & 68 & 48,71 & 0,94 \\
\hline $\mathrm{CV}(\%)$ & 18,26 & 23,52 & - & 3,63 & 11,22 \\
\hline
\end{tabular}

Médias seguidas da mesma letra não diferem estatisticamente entre si pelo teste de Tukey $(\mathrm{p}<0,05)$; **: significativo $(\mathrm{p}<0,01)$; ns: não significativo; FV: fonte de variação; GL: grau de liberdade; QM: quadrado médio; CV: coeficiente de variação 
Tabela 3 - Perfil de ácidos graxos das linhagens de amendoim precoces e tardias

\begin{tabular}{lcccccccccc}
\hline \multirow{2}{*}{ Ác. Graxo } & $\begin{array}{c}\text { BRS Pérola } \\
\text { Branca }\end{array}$ & LB 02/08 & LB & LB & LB & L. ViPE & L. GoPE & $\begin{array}{c}\text { Flo- } \\
\text { runner }\end{array}$ & BR 1 & VDP \\
\hline Palmítico & 10,06 & 11,06 & 10,29 & 11,81 & 9,83 & 9,48 & 9,23 & 11,05 & 14,31 & $\pm 0,03$ a 0,13 \\
Oleico & 50,95 & 43,81 & 45,58 & 40,47 & 48,37 & 56,23 & 58,10 & 50,12 & 40,16 & $\pm 0,08$ a 0,26 \\
Linoleico & 26,67 & 33,29 & 30,96 & 36,21 & 28,89 & 21,42 & 19,98 & 29,92 & 34,81 & $\pm 0,05$ a 0,19 \\
Linolênico & $(1)$ & $(1)$ & $(1)$ & $(1)$ & $(1)$ & $(1)$ & $(1)$ & $(1)$ & $(1)$ & - \\
Araquídico & 1,96 & 1,92 & 2,16 & 1,82 & 2,01 & 1,94 & 1,96 & 1,23 & 1,27 & $\pm 0,01$ a 0,03 \\
Gadoleico & 0,88 & 0,75 & 0,83 & 0,84 & 1,02 & 0,99 & 0,94 & 1,19 & 0,93 & $\pm 0,01$ a 0,03 \\
Behênico & 3,79 & 3,58 & 4,09 & 3,74 & 4,16 & 4,23 & 3,97 & 2,62 & 2,86 & $\pm 0,01$ a 0,05 \\
Lignocérico & 1,29 & 1,13 & 1,29 & 1,25 & 1,51 & 1,44 & 1,32 & 1,52 & 1,36 & $\pm 0,01$ a 0,03 \\
O/L & 1,9 & 1,3 & 1,6 & 1,1 & 1,6 & 2,3 & 2,9 & 1,7 & 1,1 & \\
\hline
\end{tabular}

CA - Codex Alimentarius (1996); VDP - variação do desvio-padrão das amostras; ${ }^{(1)}$ Valores abaixo de $0,1 \%$ de massa

promissoras em fase de andamento.

De acordo com dados do Economic... (1990), o ácido oleico é 10 vezes mais estável do que o linoleico e cerca de 20 vezes mais estável do que o linolênico. Em um programa de melhoramento voltado para a seleção de linhagens alto oleicas, o aumento do teor de ácido oleico e a redução nos teores do linoleico e do linolênico além de elevarem a estabilidade do óleo, reduzem ou eliminam a necessidade de hidrogenação química, responsável pela produção de ácidos graxos trans (FEHR, 2007).

Com a expansão da demanda de mercado para a produção de óleos vegetais, a possibilidade de aproveitamento do óleo de amendoim oferece uma perspectiva animadora de crescimento da lavoura, em nível extensivo ou no agronegócio familiar, para atender ao mercado de óleo comestível ou o promissor mercado de biodiesel. Nos últimos anos, os óleos vegetais têm sido utilizados como fonte de energia, sendo convertidos em ésteres metílicos para o uso como biodiesel para o transporte, ou como combustível para aquecimento (GUNSTONE, 2010). De acordo com alguns autores, o amendoim está entre as culturas com forte potencial para alimentar a matriz de matérias-primas para os mercados de óleos comestível e biocombustível, devido ao alto teor de óleo nas sementes e ao elevado potencial para produção de grãos (GUNSTONE, 2010; SANTOS et al., 2005). O óleo de amendoim puro, a propósito, foi um dos primeiros utilizados em motor do ciclo diesel, de 1896 a 1901, pelo engenheiro francês Rudolf Diesel (COSTA; ZAGONEL, 2009). Segundo Costa e Zagonel (2009), o óleo de amendoim é de excelente qualidade para a produção de biodiesel, e tem, inclusive, algumas vantagens sobre o óleo da soja. Entretanto, como é um óleo ligado à alimentação humana, tem um elevado valor agregado, o que pode impactar o custo de produção do biodiesel.

Baseando-se nos resultados obtidos neste trabalho, verifica-se que a cultivar BRS Pérola Branca é o material mais promissor, considerando-se a produtividade e o ciclo de maturação mais curto, de 110 a 115 dias, permitindo ao agricultor, dependendo de sua demanda, planejar a realização de mais de duas safras/ano. Tal prática torna-se mais difícil com as atuais cultivares rasteiras comerciais, que têm um ciclo de 130 a 140 dias, além de dormência natural, o que leva a um ciclo mais longo (GODOY et al., 1999). Por outro lado, por ter sido gerada por meio de cruzamentos entre a precoce BR 1 e a top line LViPE06, a BRS Pérola Branca tem uma tolerância moderada ao estresse hídrico, característica parcialmente herdada da BR 1, que tem alta adaptação ao ambiente semiárido nordestino (PEREIRA, 2010; SANTOS et al., 2010).

A top line LViPE-06, uma land race de grãos extralongos, coletada na região Agreste de Pernambuco, também é altamente promissora para o segmento de óleo, embora seja de ciclo mais tardio. Outra linhagem promissora deste estudo é a LGoPE-06, coletada na Zona da Mata Norte de Pernambuco, de elevada produtividade, porém, de baixa adaptação a ambientes de baixa fertilidade e com irregularidade hídrica. Esse material é um excelente recurso genético para trabalhos de melhoramento, que visa a elevação de produtividade de grãos e óleo via cruzamentos, utilizando-se, contudo, genótipos precoces, como genitores recorrentes.

\section{Conclusão}

Os genótipos mais promissores para o mercado 
oleoquímico, considerando-se a produtividade em sementes e em óleo, além da relação O/L, são BRS Pérola Branca e LViPE-06. A linhagem LGoPE-06 também é muito promissora, contudo, necessita de manejo diferenciado para garantir maior produtividade de sementes e óleo.

\section{Agradecimentos}

Os autores agradecem ao BNB (ETENE/ FUNDECI) pelo incentivo às linhas de pesquisa voltadas para o semiárido e pelo apoio financeiro aos projetos desenvolvidos pela equipe.

\section{Referências}

AMERICAN OIL CHEMISTS' SOCIETY. Official Method Ce 2-66, Seccion C. Preparation of Methyl Esters of Fatty Acids, Official Methods and Recommended Practices of the AOCS, 6th. ed. USA, 2009.

BOLTON, G. E.; SANDERS, T. H. Effect of roasting oil composition on the stability of roasted high-oleic peanuts. Journal of the American Oil Chemists' Society, v. 79, n. 02, p. 129-132, 2002.

CAMPOS-MONDRAGÓN, M. G. et al. Nutritional composition of new peanut (Arachis hypogaea L. cultivars. Grasas e aceites, v. 60 , n. 02 , p. $161-167,2009$.

COSTA, B. J.; ZAGONEL, G. F. Potencial do óleo do amendoim como fonte de biodiesel. In: SANTOS, R. C.; FREIRE, R. M. M.; SUASSUNA, T. M. F. Amendoim: o produtor pergunta, a EMBRAPA responde. Brasília: EMBRAPA, 2009. Cap. 13, p. 211-220.

CRUZ, C. D. Programa Genes: análise multivariada e simulação. Viçosa: Universidade Federal de Viçosa, 2006. 175 p.

ECONOMIC implications of modified soybeans traits. Ames, Iowa: Iowa Soybean Promotion Board; American Soybean Association, 1990. 88 p. (Special Report, 92).

FEHR, W. R. Breeding for modified fatty acid composition in soybean. Crop Science, v. 47, n. 03, p. 72-87, 2007.

GERD, J. et al. Frying performance of no-trans, low-linolenic acid soybean oils. Journal of the American Oil Chemists' Society, v. 84, n. 06, p. 557-563, 2007.

GODOY, I. J. et al. Melhoramento do Amendoim. In: BORÉM, A. (Ed.) Melhoramento de espécies cultivadas. Viçosa: Universidade Federal de Viçosa, 1999. p. 51-94.
GUNSTONE, F. D. Supplies of vegetable oils for non-food purposes. European Journal of Lipid Science, v. 113, n. 01, p. 3-7, 2010.

ISLEIB, T. et al. Compositional and sensory comparisons between normal and high oleic peanuts. Journal of Agricultural and Food Chemistry, v. 54, n. 05, p. 17591763, 2006.

JONNALA, R.; DUNFORD, N.; DASHIELL, K. New high oleic peanut cultivars grown in the Southwestern US. Journal of the American Oil Chemists' Society, v. 85, n. 02, p. 125$128,2005$.

LÉLIS, M. M. et al. Oil contents in soybean genotypes in three sowing dates. Bioscience Journal, v. 26, n. 04, p. 602$609,2010$.

MINUZZI, A. et al. Rendimento, teores de óleo e proteínas de quatro cultivares de soja, produzidas em dois locais no estado do Mato Grosso do Sul. Ciência e Agrotectnologia, v. 33, n. 04, p. 1047-1054, 2009.

OLIVEIRA, E. J.et al. Adaptabilidade e estabilidade de genótipos de amendoim de porte rasteiro. Pesquisa Agropecuária Brasileira, v. 41, n. 08, p. 1253-1260, 2006.

PEREIRA, J. W. L. Respostas fisiológica e agronômica de genótipos de amendoim sob condição de estresse hídrico. 2010. 64 f. Dissertação (Mestrado em Agronomia) - Universidade Federal Rural de Pernambuco, Recife, 2010.

SANTOS, R. C. et al. Produtividade de linhagens avançadas de amendoim em condições de sequeiro no Nordeste brasileiro. Revista Brasileira de Engenharia Agrícola e Ambiental, v. 14, n. 06, p. 589-593, 2010.

SANTOS, R. C. et al. Recomendações técnicas para o cultivo do amendoim em pequenas propriedades. Campina Grande: EMBRAPA Algodão, 2006. 7 p. (Circular técnica, 102).

SANTOS, R. C.; GODOY, J. I.; FAVERO, A. P. Melhoramento do amendoim. In: SANTOS, R. C. (Ed.). O agronegócio do amendoim no Brasil. Campina Grande: EMBRAPA Algodão, 2005. p. 17-44.

SINGKHAM, N. et al. Estimation of heritability by parentoffspring regression for high-oleic acid in peanut. Asian Journal of Plant Sciences, v. 09, n. 096, p. 358-363, 2010.

UNITED STATES DEPARTMENT OF AGRICULTURE (USDA). Foreign Agricultural Service. Disponível em: $<$ http://www.fas.usda.gov/psdonline/psdreport.aspx0?hidReport RetrievalName=BVS\&hidReportRetrievalID=918\&hidReportR etrievalTemplateID=1\#ancor $>$. Acesso em: 14 jun. 2010.

WARNER, K; FEHR, A. E. W. Mid-oleic/ultra low linolenic 